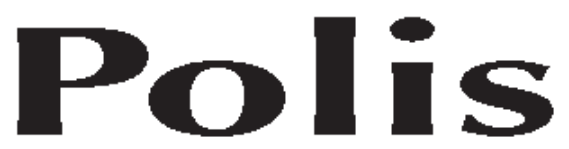

Revista de la Universidad Bolivariana Volumen 7, No 21, 2008

\title{
Los mapuches del siglo XVIII. Dinámica interétnica y estrategias de resistencia José Manuel Zavala Cepeda
}

Editorial Universidad Bolivariana, Santiago, 2008, 360 pp.

\section{Jorge Pinto Rodríguez*}

Después de casi ocho años de publicada en París, bajo el sello de la prestigiosa editorial L'Harmattan, aparece en Chile la obra del profesor José Manuel Zavala Los mapuches del siglo XVIII. Dinámica interétnica y estrategias de resistencia, originalmente titulada en francés Les Indiens Mapuche du Chili. Al igual que Alvaro Jara, Marcello Carmagnani y Guillaume Boccara, por citar algunos estudiosos chilenos y franceses que publicaron primero sus obras en Francia, Zavala puede poner recién ahora y gracias al esfuerzo de la Universidad Católica de Temuco y la Universidad Bolivariana, al alcance de los lectores españoles una obra que, sin duda, enriquece nuestra producción historiográfica y antropológica. La historia y la antropología, a pesar de los reparos que hace el profesor Zavala a la primera, y que comentaremos más adelante, se dan una vez más la mano para explicar los complejos procesos que ocurrieron en la Frontera mapuche en el siglo XVIII.

En la Introducción el autor establece sus objetivos: por una parte, dar a conocer la historia mapuche; y, por otra, abordar una faceta poco conocida del proceso colonizador, valiéndose de los testimonios dejados por los españoles que vivieron en la Araucanía, a quienes los mapuches, señala Zavala, habrían convertido en interlocutores modestos a la hora de aproximarse a su historia. Eligió el siglo XVIII por tratarse de un siglo de transición en las relaciones interétnicas ocurridas en Hispanoamérica.

Lo primero que podría decirse respecto de la obra del profesor Zavala es que ofrece una mirada novedosa de las relaciones "mapuche-huinca" y que esta mirada, instalada en el mundo indígena, ofrece un panorama que enriquece los alcances que se habían hecho sobre la Frontera, las relaciones interétnicas y, sobre todo, las complejidades de la historia

*Universidad de La Frontera, Temuco, Chile. Email: jpinto@ ufro.cl 
indígena, desde su estructura social, control del territorio, relaciones con los "otros" y los mecanismos de adaptación y resistencia que se pueden observar en el curso de la Colonia.

Parte el profesor Zavala examinando la relación que existió entre el mapuche y su territorio. El material en cual sustentó su estudio le permite afirmar que se trató de un territorio compuesto por diferentes pisos ecológicos, recorrido por los mapuches en un proceso de expansión hacia el este que muestra dos situaciones hasta ahora poco destacadas: la capacidad de adaptación del indígena a los territorios que iba ocupando y el triunfo del modelo de dispersión versus el de concentración que los caracterizó y que contrastaba con el seguido por la sociedad española. Sobre este territorio, el mapuche organizó su estructura social. De la mano de Luis Faron, Zavala examina la ruka, el lof, la kuga, los ayllarehue y vutanmapu, con el propósito de aclarar los conceptos y demostrar que no se trató de estructuras sociales rígidas y que se articulaban entre si por un principio de inclusión. Este principio hizo posible, bajo determinadas circunstancias, la constitución de grandes alianzas políticas fortalecidas por el sistema colonial. La lectura del capítulo II referido, precisamente, a esta estructura social, muestra su complejidad y la incapacidad del español de comprenderlo cabalmente, factor decisivo al momento de buscar explicaciones que permitan comprender sus dificultades para establecer relaciones con ellos.

Para el profesor Zavala este es el telón de fondo a partir del cual se puede analizar la dinámica fronteriza durante la primera mitad del siglo XVIII, sostenida en intercambios, conflictos y alianzas marcadas por el afán de controlar la tierra, procurase productos agrícolas y contar con aliados en las guerras intertribales, sobre todo en el caso de los pehuenches. De paso, habría que señalar que Zavala incluye bajo el concepto mapuche a todos los grupos que vivían al sur del Bio Bio y al este de la Cordillera, vale decir, mapuches propiamente tal, huilliches, pehuenches y aucas o moluches, todos los cuales presentan una unidad lingüística y comparten el mismo sistema simbólico.

A juicio de Zavala la incapacidad de la Corona de reducir a los mapuches a la "vida social y cristiana" terminó convirtiéndolos en un problema. Agrega el autor que se convirtieron en un doble peligro: frente a una amenaza externa, en caso de invasión por las costas de Arauco de una potencia extranjera, y por el riesgo de una rebelión interna, como ocurrió en 1723. El problema era no sólo militar, sino ideológico y social para un español que no pudo enfrentar exitosamente la "vitalidad bárbara" del mapuche, agravado por un cierto "apogeo" de los "bárbaros". Zavala señala que tres factores sostuvieron este apogeo: la expansión territorial hacia el este, incluyendo la Pampa argentina; la riqueza de ciertos grupos en la Araucanía, en particular gracias al comercio con los españoles; y, un cierto crecimiento demográfico. Paradojalmente, este apogeo acentuaba el peligro; pero, a la vez, la necesidad de someterlos definitivamente. Esto último pudo derivar en los intentos por reducirlos a pueblos que provocó la crisis de 1766-1770, concebida por algunos 
historiadores como una de los más graves del siglo XVIII. Esta crisis sirve a Zavala para poner en escena todas las complejidades de un mundo fronterizo en el cual los conflictos inter y extra étnicos se manifestaban simultáneamente en este tipo de coyuntura.

Un mecanismo de solución de aquellos conflictos fue el Parlamento, institución largamente estudiada en Chile y que Zavala analiza también con cierta detención. En su opinión, se trató de ceremonias híbridas, en las cuales los mapuches terminaron imponiendo sus reglas. Su origen estaría en las asambleas políticos-rituales que celebraban antes de la llegada de los españoles, a las cuales se adaptan estos últimos como una forma de negociación. El hecho de tener que utilizar el mapudungun da cuenta de la primera concesión hecha por el gobierno colonial, que fue seguido por otra serie de ritualidades propia del arte de hacer política entre los indígenas (el sacrificio de las "ovejas de la tierra" y el entierro de las armas, por ejemplo). Aunque en el XVIII los parlamentos se celebran en territorios controlados por los españoles y desaparecen algunos rituales del XVII, todavía se practican otros, como el de la unión de los bastones y los agasajos, que conservan tradiciones mapuches.

La guerra no desapareció. Para Zavala ésta es una condición propia de los espacios fronterizos. En el caso de la frontera hispano-mapuche opone a dos actores étnicos diferenciados, el español y el mapuche, y se manifiesta bajo diversas formas de hostilidad y violencia. El español jamás renunció a su afán de conquista y esta actitud derivó en el siglo XVIII en tres tipos de enfrentamientos: los levantamientos o rebeliones mapuches, las pequeñas razzias (malocas) realizadas por ambas partes y las expediciones militares españolas en territorio indígena. Zavala reconoce que es muy difícil comprender la guerra desde el punto de vista mapuche disponiendo sólo de documentos españoles, a pesar de lo cual ofrece algunos elementos de interpretación a partir de tres aspectos que considera importantes: en primer lugar, el hecho que los mapuches consideren la hostilidad como una forma legítima de relación social; en segundo lugar, que en esta lógica la cuestión central es el botín; y, por último, que en los actos de hostilidad contra los españoles, entren en acción grandes alianzas que obedecen a ciertos principios de organización bien establecidos.

La resistencia al español se dio también en el ámbito misionero. Zavala considera que tanto el militar como el misionero se movían por el mismo principio de dominación, aun cuando franciscanos y jesuitas practicaran modalidades distintas de evangelización frente al indígena. Los mediocres resultados obtenidos por ambas órdenes, demostrarían el peso que tuvo la resistencia mapuche en el enfrentamiento de la tradición indígena con el cristianismo. La poligamia fue un foco de permanente conflicto, originado en la incapacidad del español de entender ciertas prácticas sociales que carecían del carácter pecaminoso atribuido por los europeos. En conclusión, señala Zavala, "la conversión al cristianismo era impracticable cuando, junto con aceptar al otro y sus diferencias, no se renunciaba a las propias creencias". Al mismo tiempo, agrega, el enriquecimiento de los 
grupos que se encontraban en las cercanías de los territorios españoles gracias al comercio fronterizo y sus relaciones con las autoridades coloniales, les permitió resistir mejor la acción de los misioneros.

El intercambio comercial alcanzó en el siglo XVIII una gran intensidad, sostenido en una lógica que involucraba tanto el principio de la reciprocidad y como el del traspaso de valores de cambio. Este también es un tema largamente debatido en los últimos años, que Zavala aborda en uno de los últimos capítulos de su libro.

El análisis de la lógica mapuche de la relación con el otro cierra la obra que estamos comentando. Se trata, sin duda, de un apartado que aclara y complementa uno de los temas más propio de las relaciones interétnicas en la Frontera. Zavala comparte el juicio de varios historiadores en el sentido de que uno de los principales problemas "de la estrategia colonial española en América fue encontrar intermediaros locales capaces de movilizar a las sociedades indígenas en el sentido deseado", situación que se vio agravada en la Araucanía por la ausencia de poderes centrales y la segmentación de las organizaciones político-sociales mapuches. Las dualidades de autoridad y cosmovisión mapuche, confundieron al español. Zavala considera "que los mapuches del siglo XVIII percibían el mundo de una manera similar a los mapuches contemporáneos a través de una lógica de la dualidad que les permite organizar el mundo sobre la base de clasificaciones bipolares". Una de esas bipolaridades era la oposición español/mapuche, determinante en las relaciones interétnica que tuvieron lugar en la Araucanía. Este sería un fenómeno muy distinto al de la distancia cultural que existiría entre el mapuche y el español, utilizado por algunos historiadores como factor explicativo de la resistencia mapuche, la que terminaría minada en el siglo XIX como resultado de una dependencia económica y cultural cada vez más creciente del indígena frente a la sociedad colonial.

Zavala insiste en que la relación entre mapuches y españoles fue una relación de igual a igual, ya sea como enemigos o como aliados, pero nunca de subordinación del primero al segundo. En este sentido, el concepto Frontera refleja un problema irresuelto para los españoles en su afán por dominar al otro. La capacidad del indígena de adaptarse a situaciones nuevas y adoptar técnicas culturales europeas fueron factores determinantes en la relación de no subordinación al español. Sin embargo, concluye Zavala, el reduccionismo forzado que impuso el Estado chileno en el siglo XIX los vinculó a una agricultura de subsistencia y a una sedentarización obligada que los convirtió literalmente en "mapuches", "es decir, "hombres de la tierra".

No cabe duda que la obra de José Manuel Zavala aporta nuevos antecedentes y una interpretación novedosa para seguir explorando el siglo XVIII. Cabría felicitarlo en todo si pudiéramos pasar por alto las referencias que el profesor Zavala hace a la historiografía fronteriza. A nuestro juicio, el autor comete un error al asociar esta historiografía casi de manera exclusiva a la obra de Sergio Villalobos. Nadie discute los aportes de este 
historiador; sin embargo, nadie puede negar tampoco que una serie de trabajos aparecidos en las últimas décadas han marcado cierta distancia con sus planteamientos. Elaborado en Francia, hace ya más de 10 años, en esta edición se pudo talvez poner a punto las referencias bibliográficas para matizar los comentarios sobre la visión de los historiadores, sobre todo porque el debate con Villalobos ha excedido, en algunos casos, la cátedra y se ha expresado a través de la prensa en comentarios que van en una y otra dirección. De este modo, el apartado "Los mapuches visto por los historiadores" (pp. 24-27), creo que debería revisarse. Decir, por ejemplo, que todos los historiadores del mundo fronterizo comparten el supuesto que "cuanto más contacto pacífico e intercambio exista entre sociedad indígena y sociedad colonial, mayor es la pérdida de independencia y de identidad de la primera en relación con la segunda”, es insostenible. José Bengoa y Leonardo León, en Chile; Daniel Villar, Raúl Mandrini, Juan Francisco Jiménez, Gladys Varela y María Mercedes González Coll, en Argentina, por nombrar algunos, han venido señalando todo lo contrario y eso no se puede ignorar. También es injusto hacer referencia exclusivamente a Villalobos como representante de la historiografía fronteriza cuando se sostiene, al final (p. 318), que "la subordinación del mapuche al Chile colonial y posteriormente al Chile republicano aparece como un proceso irreversible y gradual que comienza muy tempranamente...". Menos aún se pueden descalificar, en la misma p. 318, los argumentos de algunos historiadores que no se exponen y que se confunden con los planteamientos de Villalobos. Declarar que éstos entienden la "relación fronteriza" como una relación colonial que no cristalizó "de la manera deseada" y que este juicio se oculta en un lenguaje que encierra una cierta dosis de procacidad ("aunque sin confesarlo", dice Zavala), me parece demasiado aventurado.

En fin, este punto como otros que se exponen en un libro no menor, serán motivo de distintas apreciaciones que no sólo justifican su lectura, sino el sentido mismo de cualquier aporte sustentado en la intención de contribuir a comprender mejor un pasado que ha dejado ya de ser patrimonio exclusivo de los historiadores. Un libro que no despierte polémica no vale la pena leerlo y esto no ocurrirá con este. 